\title{
Analysis of Performance, Emission and combustion characteristics of a single cylinder VCR engine when run on blends of 1-octanol and Diesel
}

DOI : 10.36909/jer.ICCEMME.15723

\author{
${ }^{1}$ Ashish Kumar Singh, ${ }^{2}$ Amardeep*, ${ }^{3}$ Vinod Kumar Yadav \\ ${ }^{1}$ Mechanical Engineering Department, KIET Group of Institutions, Delhi NCR, Ghaziabad- \\ 201206, India. \\ ${ }^{2,3}$ Department of Mechanical Engineering, G L Bajaj Institute of Technology and Management, \\ Greater Noida, Uttar Pradesh -201310, India. \\ *Corresponding Author: Email- amardce2012@gmail.com
}

\begin{abstract}
Phenomenal Changes are taking place in the world. The energy consumption of the country has grown many folds over the past few years, thereby putting pressure on the fossil fuel reserves. Though, recently due to COVID-19, the price of crude oil has fallen since few months but it would again rise which would lead to heavy expenditure over imports of crude petroleum. Also the fossil fuels increase the problem of global warming and carbon emissions. Alternate fuel such as alcohols poses a sustainable alternative solution of the problem. In the present investigation, Blends of 1-octanol are formed with neat diesel i.e. OC5, OC-10, OC-15 \& OC-20 and analyzed for efficiency, fuel economy and effluents of the single cylinder variable compression ratio engine. It was perceived that there was increment in viscosity of the blends containing n-octanol while the heating value lowered by increasing the absorption of 1-octanol. The peak BTE and lowest fuel consumption was found to be with blend containing 20\% 1-octanol. Lower CO and UBHC emissions were reported with the addition of 1-octanol in the different blends formed.
\end{abstract}

Key words: 1-octanol, performance, emission, combustion, variable compression ratio and diesel engine 


\section{INTRODUCTION}

Energy plays a essential role in present scenario. With bulk requirement for energy, there is heavy dependence on fossil fuels. A substantial amount of fossil fuels' consumption is shared by transportation sector. The internal combustion engines besides putting pressure on fossil fuels also emit harmful emissions of $\mathrm{NOx}, \mathrm{CO}_{2}, \mathrm{CO}$ and smoke. According to report by BP energy, the total oil consumption per day in India corresponds to 5156 thousand barrels per day. The country has a Reserve to production ratio of 18.7 years and shares $1.5 \%$ of total proven oil reserves. The country spent near 102 billion on the imports of the crude oil in the financial year 2019-2020 (BP statistical Review 2019). It therefore necessitates the use of alternative fuel for the substitution of diesel fuel in internal combustion engines. Alternate fuels besides providing energy security to the world it also creates employment opportunities for the large number of people. Reports on the use of alcohol are known since 1907. It was primarily used in gasoline engines. However, the alcohol can be utilised in compression ignition engines as well. The alcohols have several advantages over the different alternate fuels available (Yusria et. al, 2017).

\section{LITERATURE REVIEW}

The utilization of alcohols in IC engines has been recognized firstly in 1920 specifically with regard to gasoline engine. Researchers around the world did significant work on use of methyl and ethyl alcohol in diesel engine. However, comparatively lesser work can be seen done towards higher chain alcohols due to the difficulties faced in their commercial production.

Substantial research has been done on the different alternatives for diesel fuel. (Akhtar et. al, 2015) examined the production of iso-octanol which is an active biofuels. He showed that the properties of both the fuels (n-octanol and iso-octanol) were almost similar and iso-octanol can be prepared by the help of microbes. (Koul, 2015) conducted experiment on single cylinder diesel engine fuelled with iso-octanol and diesel fuel blends. The engine trials were 
conducted on different blends. There was increment in BTE and the BSFC was significantly lowered. The Lower $\mathrm{CO}$ and $\mathrm{NO}_{\mathrm{x}}$ were reported depicting improved combustion inside the engine. Visual inspection was done to check the homogeneity of the blends. The blends were observed to be highly stable as well. (Deep et. al, 2018) was performed experimental trials on original agricultural unmodified diesel engine fuelled with ethanol and orange peel oil blends. They examined that there was slight reduction in efficiency and the NOx was also lowered for different blends that were tested. (Keerthi et. al, 2013) conducted an experiment by varying injection pressure in diesel engine fuelled with $10 \%$ iso-butanol. The efficiency of the engine was improved and BSFC was lowered as well. It was reported that the addition of 1- octanol to biodiesel and diesel blends improved the efficiency and fuel economy of engine and effluents were lowered as well (Sriram. et al, 2017). (Deep et. al, 2014a) reported that the properties of 1-Octanol were almost similar to mineral diesel; the addition of 1 octanol to mineral diesel lowered the NOx while $\mathrm{HC}$ effluents were triggered and efficiency was slightly lowered with increment in CO and smoke opacity. (Sinha et. al, 2019) reported that on blending $20 \%$ n-octanol to Kharanja biodiesel and diesel blend, efficiency of the engine was increased and in-cylinder pressure and heat release rate was marginally increased. (Ramalingam et. al, 2020). It was reported that utization of n-butanol with blends of diesel and orange peel methyl ester increases the efficiency of the engine and lowers the carbon mono-oxide emission (Deep et. al, 2015). (Fernández et. al, 2012) observed that utilization of upto $30 \%$ butanol or upto $25 \%$ pentanol can substitute for diesel fuel in enact diesel engines ensuring satisfactory efficiency and effluents of the engine. (Liu et. al, 2011) conducted experimental trials and reported that the methanol is immiscible with diesel fuel leading to phase separation when it is mixed with mineral diesel. The methanol and diesel emulsion thereby can be generated by using a rotating packed bed. This emulsifying method rectified the homogeneity problem faced during blending. (Saroj et. al, 2016) performed the taguchi optimisation on the formation of jathorpha oil ethyl ester and found that maximum 
percentage yield is obtained at Molar ratio $5: 1,1 \%$ catalyst $\%$, at $65^{\circ} \mathrm{C}$ reaction temperature and 120min.reaction time. (Gautam et. al, 2016a) reported that addition of ethanol in jatropha biodiesel and diesel blends reduced the density and viscosity of blends thereby lowering the effluents and increasing the efficiency. (Gautam et. al, 2016b) conducted an experiments and they found that there was increment in BTE and BSFC was lowered, The CO and UBHC and smoke opacity were significantly improved. They announce that the addition of n-butanol to the blends of diesel and jatropha biodiesel increases the efficiency of the engine and effluents of the engine are enhanced (Gautam et. al, 2018a). (Gautam et. al, 2018b) reported the use of jatropha biodiesel as domestic fuel for lamp and stoves and thereby saving the conventional fuel and its production could provide employment opportunities with its ease of production in different parts of the country. (Singh et. al, 2019) conducted experimental trials on diesel engine fuelled with diesel fuel, kusum oil biodiesel and n-butanol. They reported that efficiency and fuel consumption of the engine was significantly enhanced and effluents of the engine were lowered. (Gautam et. al, 2020) performed the optimization of parameters involved in preparation of jatropha ethyl ester using response surface methodology. They concluded that maximum yield was observed with8.5 molar ratio at $89.67 \mathrm{~min}$ reaction time and $70.1^{\circ} \mathrm{C}$ reaction temperature with $0.62 \mathrm{wt} \%$ of catalyst. (Gautam et. al, 2019) observed that utilisation of lower alcohols and bio-diesel in diesel engine enhanced the efficiency and fuel consumption of the engine and tends to lower the effluents of the diesel engine. (Deep et. al, 2014b) performed experimental trials on diesel engine fueled with Iso-propyl alcohol and orange peel biodiesel and reported that efficiency and fuel economy was enhanced and effluents were lowered.

The above literature depicts that comprehensive work has not been done on 1-octanol and diesel fuel blends. 


\section{BLEND FORMATION}

1-octanol and diesel were found to be miscible and hence, blend can easily be formed by mixing 1-octanol and diesel in a fixed ratio (volume by volume). The nomenclatures used for the blends preparation are shown in table -1 .

Table-1: Nomenclatures used for the blends preparation

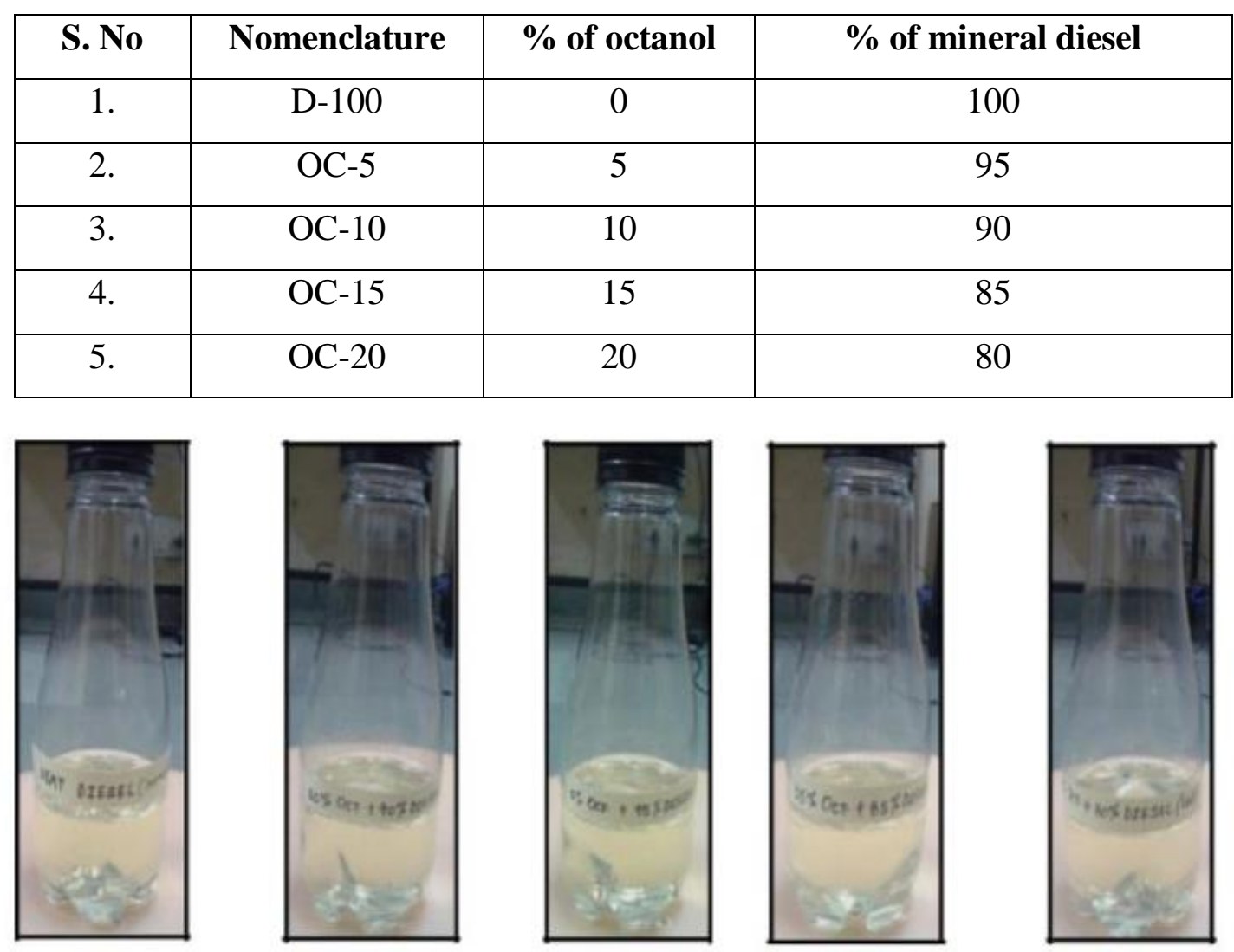

Figure 1: Various blends formed during the investigation

\section{EXPERIMENTAL SETUP}

The various blends and diesel fuel were tested on unmodified single cylinder four strokes VCR Diesel engine. The experimental setup is shown in figure 2. The technical specifications of the engine used are described in table 1. 
Table 1: Technical details of the diesel engine

\begin{tabular}{|l|l|}
\hline Origin & Kirloskar \\
\hline Peak Brake Power $(\mathrm{kW})$ & 3.5 \\
\hline Speed $(\mathrm{rpm})$ & 1500 \\
\hline Number of Cylinder & One \\
\hline Bore $\times$ Stroke $(\mathrm{mm})$ & $87.5 \times 110$ \\
\hline Compression Ratio & $17.5: 1$ \\
\hline Variable compression ratio & 12 to 18 \\
\hline Cooling System & Water Cooled \\
\hline
\end{tabular}

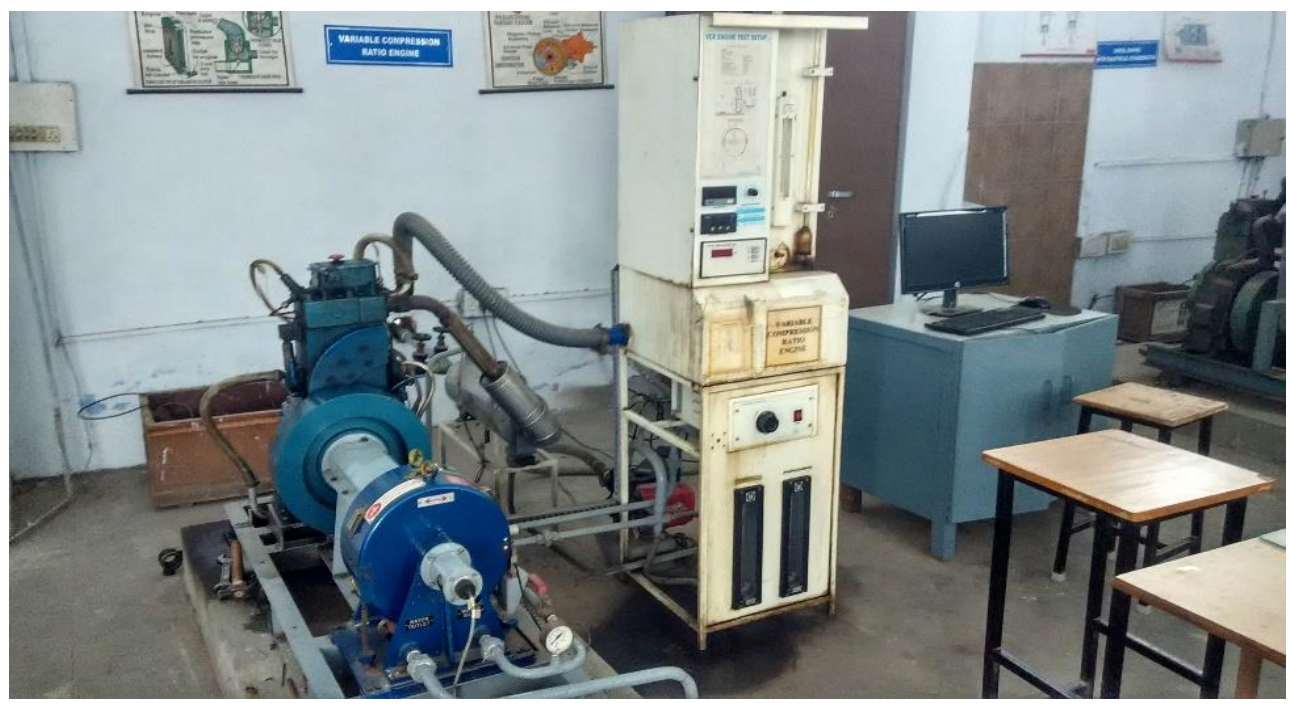

Figure 2: The experimental setup

RESULTS \& DISCUSSION

\section{COMPARISON OF PROPERTIES}

The physico-chemical properties of diesel and 1-octanol blends and mineral diesel were tested on Anton parr density meter, kinetic viscometer and bomb calorimeter. The viscosity of blends containing n-octanol was found to be higher than mineral diesel. The heating value of blends containing n-octanol was marginally lower. The density of blends containing $n$ octanol was also lower compared to mineral diesel. The various Physico-chemical Properties are expressed in table 2. 
Table 2: Physico-chemical Properties Comparisons of various blends

\begin{tabular}{|c|c|c|c|c|}
\hline S. No. & Blend & $\begin{array}{c}\text { Density } \\
\left(\mathbf{K g} / \mathbf{m}^{\mathbf{3}}\right)\end{array}$ & $\begin{array}{c}\text { Viscosity } \\
\left(\mathbf{m m}^{\mathbf{2}} / \mathbf{s e c}\right)\end{array}$ & $\begin{array}{c}\text { Calorific value } \\
(\mathbf{M J} / \mathbf{K g})\end{array}$ \\
\hline 1 & D100 & 810 & 3.123 & 45.49 \\
\hline 2 & OC5 & 808.3 & 3.231 & 44.38 \\
\hline 3 & OC10 & 807.1 & 3.332 & 43.49 \\
\hline 4 & OC15 & 806.2 & 3.586 & 43.24 \\
\hline 5 & OC20 & 805.4 & 3.951 & 42.94 \\
\hline
\end{tabular}

\section{PERFORMANCE CHARACTERISTICS}

The engine efficiency and fuel consumption when run on different blends were analyzed and summarized in this section. The efficiency and fuel economy thus obtained were compared with baseline diesel fuel.

\section{BRAKE THERMAL EFFICIENCY (BTE)}

The experimental trials depicted that the BTE increases on addition of percentage by volume of 1-octanol in mineral diesel shown in figure 3. The peak BTE is observed for the blend contains $20 \%$ n-octanol owing to the promoted combustion inside the engine cylinder due to the availability of the oxygen in the fuel. Similarly, for other blends, brake thermal efficiency increased in accordance to the increase in percentage by volume of octanol mixed with diesel. The BTE in case of diesel was found to be $25.3 \%$, while blend contain $20 \%$ n-octanol was having an efficiency of $29.5 \%$, similarly the efficiencies of blend contain $5 \%$ n-octanol, blend contain $10 \%$ n-octanol and blend contain $15 \%$ n-octanol were found to be $27 \%, 27.4 \%$ and $28.6 \%$ respectively. The results are in close confirmation with the analysis done by Koul et.al, 2015, Deep et. al, 2014, Sinha et. al, 2019. 


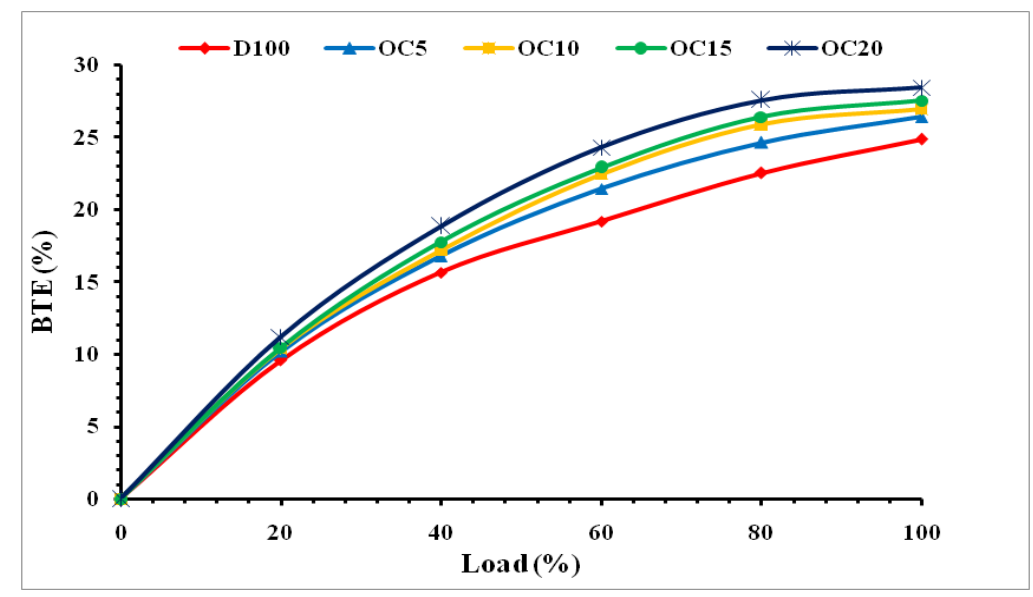

Figure 3: Brake thermal efficiency in correspondence to \% load on engine

\section{BRAKE SPECIFIC FUEL CONSUMPTION (BSFC)}

The experimental trials depicted the BSFC for different with respect to percentage load on the engine shown in figure 4. Figure depicts that the BSFC lowered with the addition of noctanol in the mineral diesel. This can be ascribed to increase in oxygen content of blends making it to produce more energy per combustion stage. The peak BSFC was observed for diesel at $20 \%$ loading and has a value of $0.88 \mathrm{~kg} / \mathrm{kWh}$. It was observed that the lowest at same load for blend contain $20 \%$ n-octanol. The values for BSFC were $0.82,0.79,0.77$ and $0.76 \mathrm{~kg} / \mathrm{kWh}$ for blends contain $5 \%$ n-octanol, blends contain $10 \%$ n-octanol, blend contains $15 \%$ n-octanol and blends contain $20 \%$ n-octanol respectively. The results are in close confirmation with the analysis done by Koul et.al, 2015, Deep et. al, 2014, Sinha et. al, 2019.

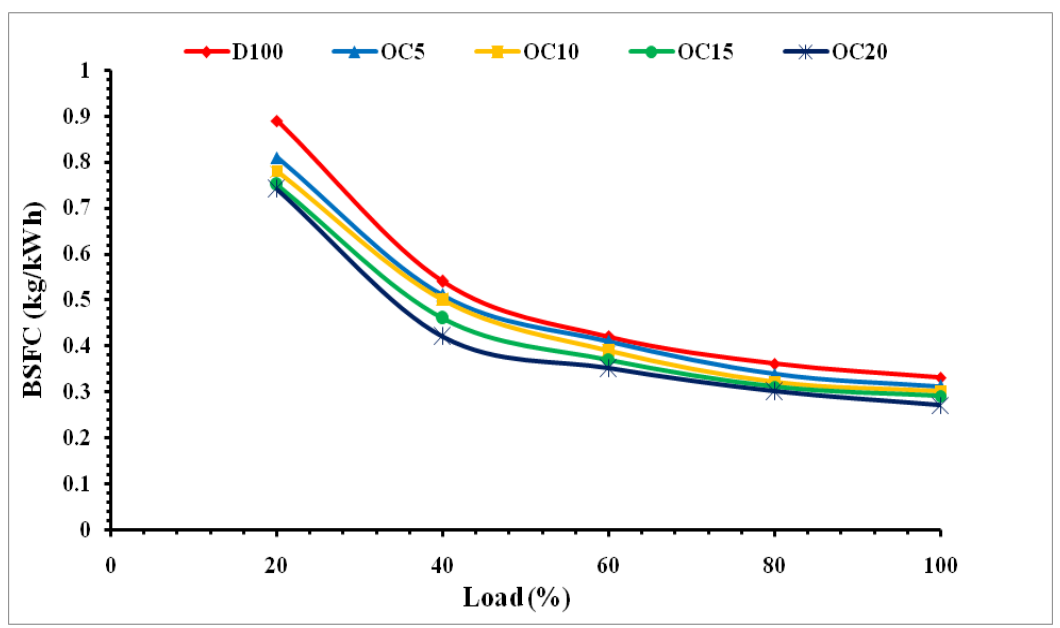

Figure 4: Brake specific fuel consumption in correspondence to \% load on the engine 


\section{EXHAUST \& EMISSION CHARACTERISTICS}

Exhaust temperature and effluents of the engine were analysed and discussed subsequently.

\section{EXHAUST TEMPRATURE}

The experimental trials indicate that the exhaust temperature observed with blend containing $20 \%$ n-octanol was utmost among all the blends that are depicted in figure 5 also. It can be perceived that there was a small increment in the exhaust temperature with addition of noctanol in the blends. It may be ascribed to better combustion inside the engine due to the better availability of oxygen. The peak exhaust temperature corresponded to the blend containing $20 \%$ n-octanol having a value of $277.5^{\circ} \mathrm{C}$ and lowest was $269.73^{\circ} \mathrm{C}$ for mineral diesel.

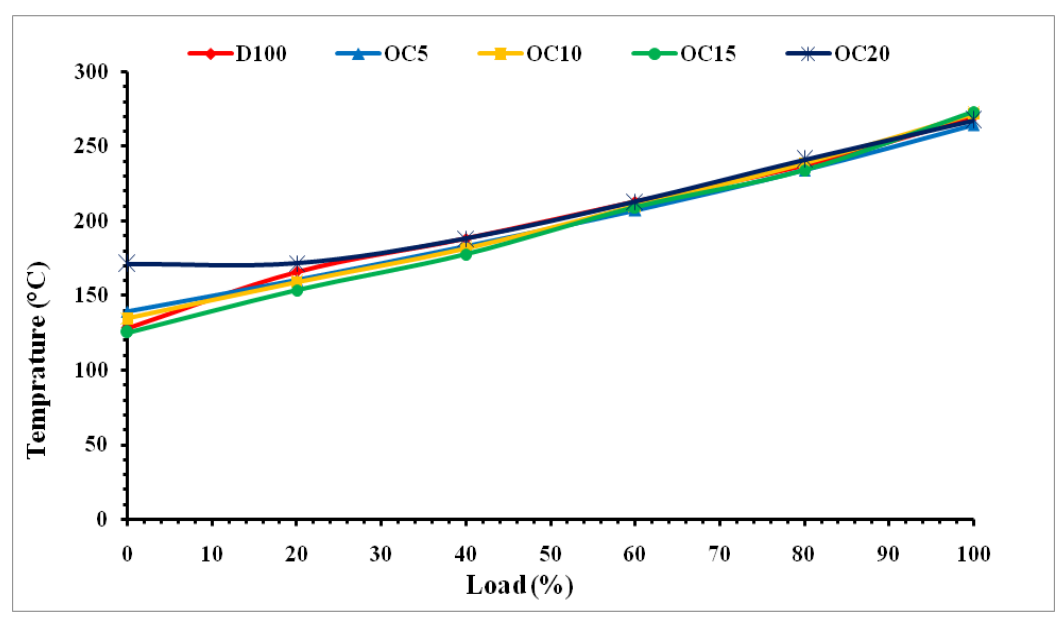

Figure 5: Exhaust temperature in correspondence to \% load on the engine

\section{CARBON MONOOXIDE (CO) EMISSIONS}

The experimental trials indicating $\mathrm{CO}$ emissions when engine was run on the different test fuels in correspondence to percentage load is shown in figure 6. It can be depicted that the $\mathrm{CO}$ emissions of the engine is lower for OC-20 blend at all the loads. This can be ascribed to promoted combustion process inside the engine cylinder because of better availability of oxygen present in n-octanol. At peak loads the $\mathrm{CO}$ emissions increases for all the blends containing octanol because of incomplete combustion owing to more fuel injected at peak load. The results are in close confirmation with the analysis done by Koul et.al, 2015, Deep 
et. al, 2014, Sinha et. al, 2019.

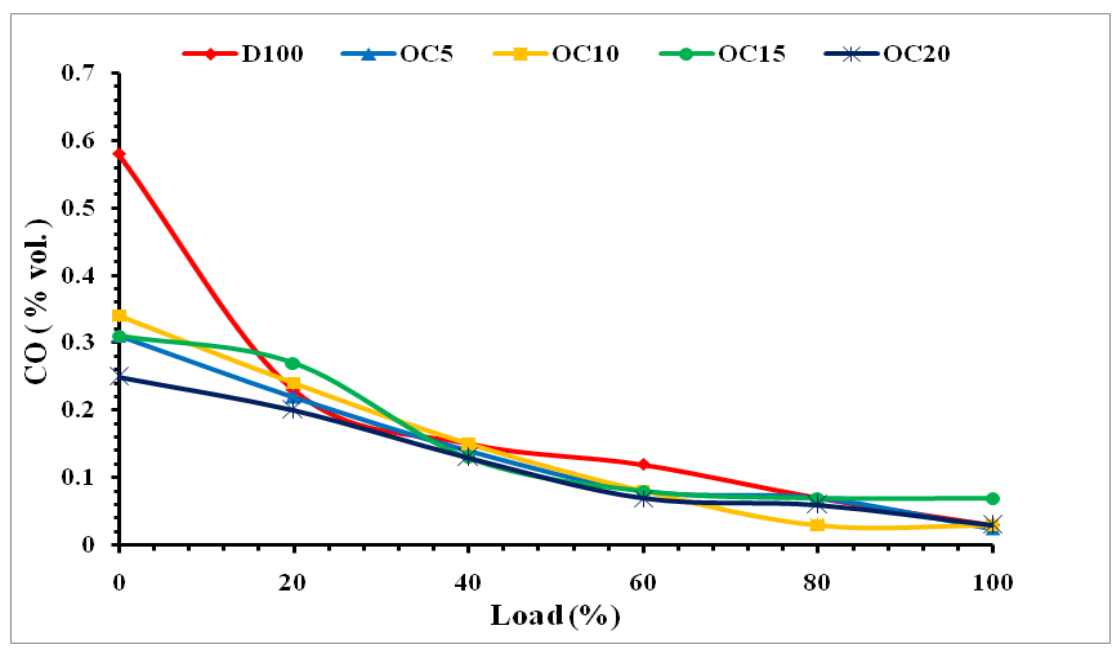

Figure 6: $\mathrm{CO}$ emissions in correspondence to \% load on the engine

\section{UNBURNT HYDROCARBON (UBHC) EMISSIONS}

The experimental trials indicating the unburnt hydrocarbon emissions of the engine for the different test fuels in correspondence to the percentage load is shown in figure 7. Trials depict that the unburnt hydrocarbon emissions were lowest for the blend containing $20 \% \mathrm{n}$ octanol. This can be ascribed to better combustion inside the engine cylinder owing to better availability of the oxygen inside the cylinder. For the blends containing lesser percentage of octanol, the unburnt hydrocarbon emission of the engine increased with respect to blend containing $20 \%$ n-octanol.

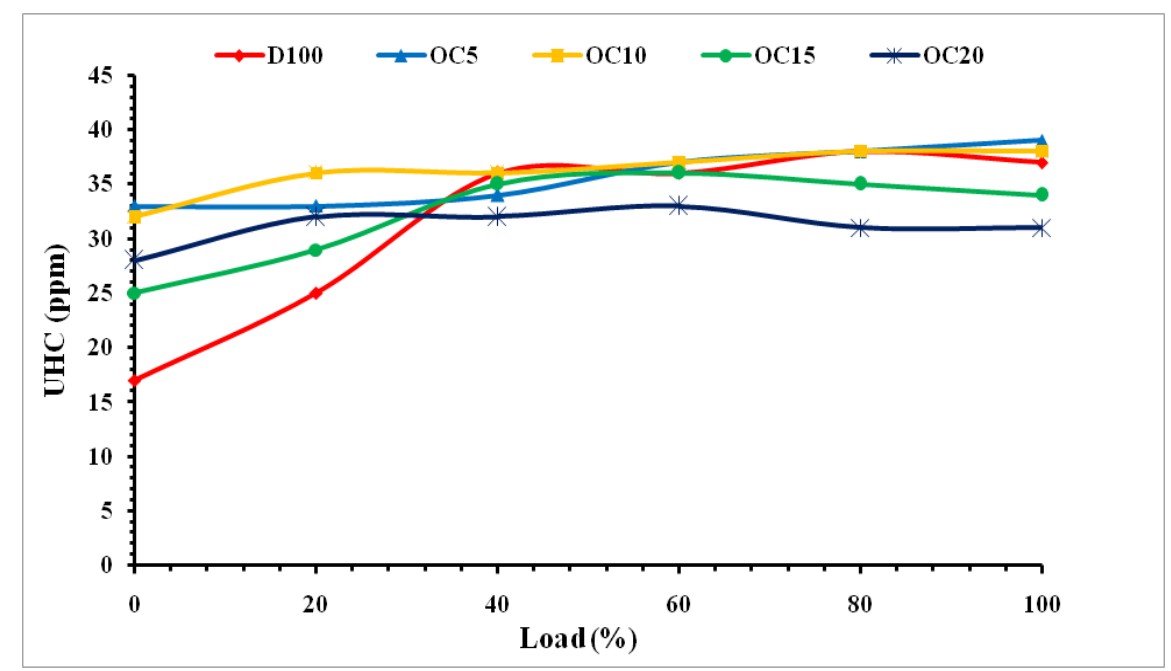

Figure 7: UBHC in correspondence to \% Load on the engine COMBUSTION ANALYSIS 
The in-cylinder pressure corresponding to the different blends at peak load condition is depicted in figure 8 .

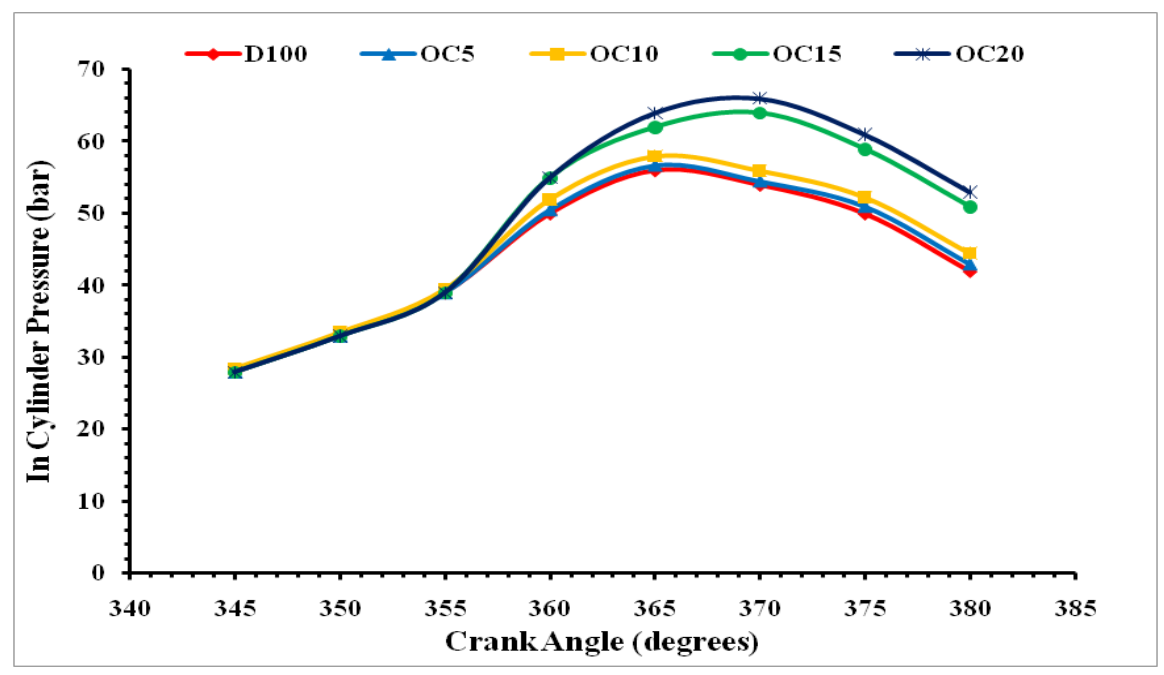

Figure 8: in-cylinder pressure in correspondence to \% load on the engine

The experimental trials showed the increment in in-cylinder pressure with increase in percentage by volume of n-octanol in the diesel. It was also perceived that the peak in cylinder pressure was 68.23 bar at 369 o CA rotation for blend containing $20 \%$ n-octanol. The peak in cylinder pressure for baseline diesel was 58.12 bar at 3660 of CA rotation which increased to 58.77 bar at 367 o for blend containing 5\% n-octanol, 59.12 bar at 367 o for blend containing $10 \%$ n-octanol and 66.4 bar at 3690 of CA rotation for blend containing $15 \% \mathrm{n}$ octanol. The peak in cylinder pressure for $20 \%$ n-octanol blend occurred with ignition delay greater than that of diesel. This can be ascribed to the lower cetane rating of n-octanol as compared to mineral diesel. The in-cylinder pressure for different blends was greater than baseline diesel because of improved combustion. The results are in close confirmation with the analysis done by Koul et.al, 2015, Deep et. al, 2014 and Sinha et. al, 2019.

\section{CONCLUSIONS}

The present examination was carried out on unmodified water cooled single cylinder diesel engine with variable compression ratio. The prime objective was to assess the aptness of noctanol and diesel fuel blends as an alternate fuel for diesel engine and to compare 
combustion characteristics and thereby observing the performance and effluents of the engine. The results indicated that the engine BTE with blends containing n-octanol was slightly better. The physico-chemical properties analysis indicated that viscosity of the noctanol and diesel blends was greater with respect to mineral diesel. Whereas, the net heating value of all the blends was lesser as compared to mineral diesel.

The peak BTE was $29.5 \%$ corresponding to OC-20 blend. The BTE of engine with OC-5, OC-10 and OC-15 blends were greater than with mineral diesel. Thus, it can be concluded that on blending diesel with 1-octanol leads to increment in BTE. The lowest BSFC was 0.76 $\mathrm{kg} / \mathrm{kWh}$ corresponding to OC-20 blend. The BSFC of engine with OC-5, OC-10 and OC-15 blend was also lesser than BSFC with mineral diesel. With regard to emissions, CO emissions saw a decrease, thereby indicating promoted combustion of the fuel. And also, the HC emissions were lowered on increasing the percentage by volume of 1-octanol in diesel, the minimum being that of OC-20 blend at full load. The emissions characteristics indicated the possibility of reduced environmental threat with the increased usage of octanol in diesel. The results from the experiment showed that the operational characteristics of single cylinder diesel engine were improved on blending percentage by volume of n-octanol up to $20 \%$ in the mineral diesel fuel.

\section{REFERENCES}

BP 2019, statistical Review of the world energy Report.

\section{I.M. Yusria,, R. Mamata, G. Najafib, A. Razmana, Omar I. Awada, W.H. Azmia,} W.F.W. Ishakc, A.I.M. Shaifu, 2017, Alcohol based automotive fuels from first four alcohol family in compression and spark ignition engine: A review on engine performance and exhaust emissions Renewable and Sustainable Energy Reviews 169181.

Amar Deep, Rakesh Kumar \& Naveen Kumar, 2018, Studies on the use of orange peel oil 
and ethanol in an unmodified agricultural diesel engine, Energy Sources, Part A: Recovery, Utilization, and Environmental Effects, https://doi.org/10.1080/15567036.2018.1549160.

Koul, Rashi, 2015, Performance characteristics of single cylinder diesel engine fuelled with 1-Octanol diesel blends. International Journal of latest trends in Engineering and Technology.

Florian Kremer, Lars M. Blank, Patrik R. Jones and M. Kalim Akhtar, 2015, A comparison of the microbial production and combustion characteristics of three alcohol biofuels: ethanol, 1-butanol, and 1-octanol'Frontiers in Bio Engineering and Biotechnology, doi: 10.3389/fbioe.2015.00112.

K. Keerthi, Kiran C. Kariankal, S. Sravya, 2013, Performance characteristics of four stroke single cylinder diesel engine with $10 \%$ iso-butanol at different injection pressures. International Journal of Modern Engineering Research. Vol 3, Issue 1, pp-311-316 ISSN: $2249-6645$.

V.Sriram, Jeyajeevahan, G.Mageshwaran, G.Brittojoseph \& R.B.Durairaj, 2017, Engine performance and emission characteristics of 1-octanol blended bio-diesel in a single cylinder diesel engine, International Journal of Mechanical and Production Engineering Research and Development Vol. 7, Issue 6, 623-630.

Deep, A., Kumar, N., Karnwal, A., Gupta, D. et al., 2014, Assessment of the Performance and Emission Characteristics of 1-Octanol/Diesel Fuel Blends in a Water Cooled Compression Ignition Engine, SAE Technical Paper 2014-01-2830, doi:10.4271/2014-012830.

Sunil Kumar Sinha, Naveen Kumar, Rajesh Kumar, 2019, Performance Emission of NOctanol - Biodiesel Blend in Diesel Engine, International Journal of Recent Technology and Engineering (IJRTE) ISSN: 2277-3878, Volume-8 Issue-4. 
Selvakumar Ramalingam and N. V. Mahalakshmi, 2019, Influence of Moringa oleifera biodiesel-diesel-hexanol and biodiesel-diesel-ethanol blends on compression ignition engine performance, combustion and emission characteristics, Royal Society of Chemistry, doi: 10.1039/c9ra09582a.

Deep, A., Kumar, N., Kumar, M., Singh, A. et al, 2015, Performance and Emission Studies of Diesel Engine Fuelled with Orange Peel Oil and N-Butanol Alcohol Blends," SAE Technical Paper 2015-26-0049, doi:10.4271/2015-26-0049.

Javier Campos-Fernández, Juan M. Arnal, Jose Gómez, M. Pilar Dorado, 2012, A comparison of performance of higher alcohols/diesel fuel blends in a diesel engine, Applied Energy, Volume 95, Pages 267-275, ISSN 0306-2619, https://doi.org/10.1016/j.apenergy.2012.02.051.

Y. Liu, W. Jiao and G. Qi, 2011, Preparation and Properties of Methanol-Diesel Oil Emulsified Fuel under High-Gravity Environment," Renewable Energy, Vol. 36, No. 5, pp. 1463-1468.

Saroj, S. K., Gautam, R., \& Shubhendu, N, 2016, Reduction of free fatty acid of jatropha oil using taguchi approach, International Journal of Scientific Engineering and Applied Science (IJSEAS)-Volume-2, Issue-9, ISSN: 2395-3470.

Raghvendra Gautam\& Naveen Kumar, 2016, Effect of ethanol addition on the properties of Jatropha ethyl ester, Energy Sources, Part A: Recovery, Utilization, and Environmental Effects, Taylor \& Francis 38:23, 3464-3469, DOI: 10.1080/15567036.2016.1145766.

Raghvendra Gautam, Naveen Kumar, Harveer Singh Pali \& Parvesh Kumar, 2016 Experimental studies on the use of methyl and ethyl esters as an extender in a small capacity diesel engine, Biofuels, Taylor \& Francis 7:6, 637-646, DOI: 10.1080/17597269.2016.1187538.

Gautam, R., \& Kumar, N, 2018, Performance emission and combustion studies of diesel 
engine on Jatropha ethyl ester and its higher alcohol blends. International Journal of Global Warming, Inderscience. 14(2), 159-169. ISSN 1758-2091.

Raghvendra Gautam, 2018, Decreasing of Agricultural Costs for The Indian Farmer by using Jatropha Easters, International journal of basic and applied research, ISSN 22493352 (P) 2278-0505 (E).

Singh, V., Agarwal, T., Saroha, N., and Gautam, R., 2019, Performance Emissions and Combustion Analysis of CI Engine Using Ethyl Ester Kusum Oil and Butanol Blends, SAE Technical Paper 2019-01-0568, https://doi.org/10.4271/2019-01-0568.

Gautam, R., Ansari, N., Sharma, A., \& Singh, Y., 2020, Development of the Ethyl Ester from Jatropa Oil through Response Surface Methodology Approach. Pollution, 6(1), 135147, doi: 10.22059/poll.2019.284612.642.

Gautam, R., Ansari, N. A., Thakur, P., Sharma, A., \& Singh, Y., 2019, Status of Bio Fuel in India with Production and Performance Characteristics: A Review. International Journal of Ambient Energy, 1-59, https://doi.org/10.1080/01430750.2019.1630298.

Deep, A., Kumar, N., Gupta, D., Sharma, A. et al., 2014, Potential Utilization of the Blend of Orange Peel Oil Methyl Ester and Isopropyl Alcohol in CI Engine, SAE Technical Paper 2014-01-2778, doi:10.4271/2014-01-2778. 